Available online on 15.07.2018 at http://jddtonline.info
Journal Of Drug Delivery and Therapeutics
$\begin{gathered}\text { Open Access to Pharmaceutical and Medical Research } \\ \text { (2011-18, publisher and licensee JDDT, This is an Open Access article which permits unrestricted non- } \\ \text { commercial use, provided the original work is properly cited }\end{gathered}$

Open $\odot$ Access

Research Article

\title{
A VALIDATED RP-HPLC ASSAY METHOD FOR DETERMINATION OF GEMCITABINE LOADED NANOSIZED SOLID LIPID NANOPARTICLES
}

\author{
Namrata Soni, Neetu Soni, Pramode W. Ramteke, Himanshu Pandey \\ Department of Pharmaceutical Sciences, Faculty of Health Sciences, Sam Higginbottom Institute of Technology and Sciences, \\ Naini, Allahabad, (U.P. ) 211007, India.
}

\begin{abstract}
A novel reverse phase HPLC assay method has been developed and validated for the simultaneous determination of Gemcitabine Hydrochloride $(\mathrm{dFdCH})$ along with solid lipid nanoparticles SLNs and conjugated with mannose to targeting the lungs for chemotherapy. Methanol was used as the extracting solvent for preparation of tissue sample. Methanol: Ammonium acetate buffer; 10:90 v/v (pH 5) was the mobile phase at flow rate $1.5 \mathrm{~mL} / \mathrm{min}$ at pressure of 102/101 bars using Luna Phenomenex, C18 $(4.6 \mathrm{~mm} \times 250 \mathrm{~mm} ; 5 \mu \mathrm{m}$ bead size $)$ at wavelength $269 \mathrm{~nm}$. The column oven temperature was optimized at $35^{\circ} \mathrm{C}$. The biodistribution studies were conducted to evaluate the target potential at the sites of interest in liver, spleen, lung and kidney respectively, the calibration curve was found to be linear over the concentration range of $100-5000 \mathrm{ng} / \mathrm{mL}\left(\mathrm{r}^{2}=0.9980, \mathrm{r}^{2}=0.9980, \mathrm{r}^{2}=0.9990, \mathrm{r}^{2}=1\right.$ respectively). Plain drug have greatest access to liver and secondarily to spleen and then kidney but on the contrary the concentration of drug was greatest in lung when treated with mannosylated SLNs, data suggested that the mannose attachment has provided the access for the drug in the lungs via the formulation in greater quantity than free drug due to interaction of mannose with mannose receptors present on lung macrophages. The developed method was validated in accordance to ICH guidelines.
\end{abstract}

Keywords: High Performance Liquid Chromatography, Mannosylated SLNs, Macrophage Mannose, Receptor (MMR), Lung Cancer, Gemcitabine Hydrochloride.

Article Info: Received 02 June, 2018; Review Completed 10 July 2018; Accepted 12 July 2018; Available online 15 July 2018

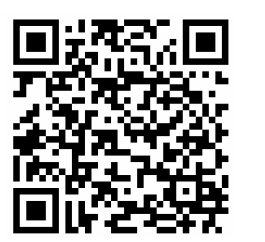

\section{Cite this article as:}

Soni N, Soni N, Ramteke PW, Pandey H, A validated RP-HPLC assay method for determination of gemcitabine loaded nanosized solid lipid nanoparticles , Journal of Drug Delivery and Therapeutics. 2018; 8(4):308-313 DOI: http://dx.doi.org/10.22270/jddt.v8i4.1800

Mrs. Namrata Soni, Assistant Prof., Department of Pharmaceutical Sciences, Faculty of Health Sciences, Sam Higginbottom Institute of Technology and Sciences, Naini, Allahabad (U.P.)

Abbreviations: dFdCH: 2'-2'-difluorodeoxycitidine hydrochloride (Gemcitabine), SLNs: Solid lipid nanoparticles, dFdC-SLNs: gemcitabine loaded SLNs, dFdC-MSLNs: gemcitabine loaded mannosylated SLNs.

\section{INTRODUCTION}

Gemcitabine is a pyrimidine antimetabolite. Chemically it is 2'-2'-difluorodeoxycitidine $(\mathrm{dFdC})$. This molecule bearing fluorine atom replaces the hydroxyl group and the hydrogen atom at the 2'-position of cytidine. After its anabolism to diphosphate and triphosphate metabolites, gemcitabine inhibits ribonucleotide reductase and competes with 2' - deoxycytidine triphosphate for incorporation into DNA. These effects produce cell-cycle-specific cytotoxicity. ${ }^{1-2}$

Selective and site-specific administration of anticancer drugs may help in overcoming low survival rate and cytotoxic effects on normal tissues. Even highly toxic agents could be rendered safer and more effective, if it could be possible to direct them specifically into the tumor cells. This is because of accomplishment of higher drug concentration within the tumor cells, with fewer or no distribution towards normal tissues. To achieve the above mentioned goal we planned to construct mannose anchored SLNs nano-constructs loaded with anticancer bioactive for efficiently targeting the lung cancer cells. ${ }^{3-}$ 7

SLNs are typically spherical with an average diameter between 10 and 1000 nanometers. Solid lipid 
nanoparticles possess a solid lipid core matrix that can solubilize lipophilic molecules. The lipid core is stabilized by surfactants (emulsifiers). The term lipid is used here in a broader sense and includes triglycerides (e.g. tristearin), diglycerides (e.g. glycerol bahenate), monoglycerides (e.g. glycerol monostearate), fatty acids (e.g. stearic acid), steroids (e.g. cholesterol), and waxes (e.g. cetyl palmitate). All classes of emulsifiers (with respect to charge and molecular weight) have been used to stabilize the lipid dispersion. It has been found that the combination of emulsifiers might prevent particle agglomeration more efficiently ${ }^{8-9}$

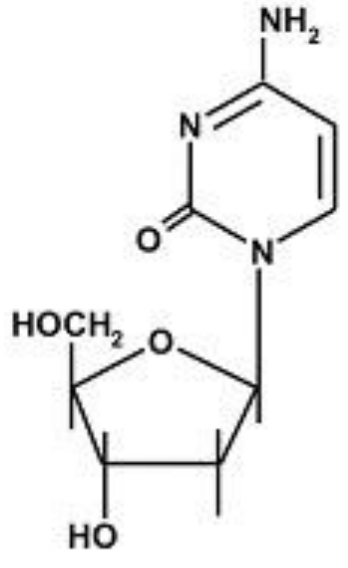

Dé-oxy-cytidine

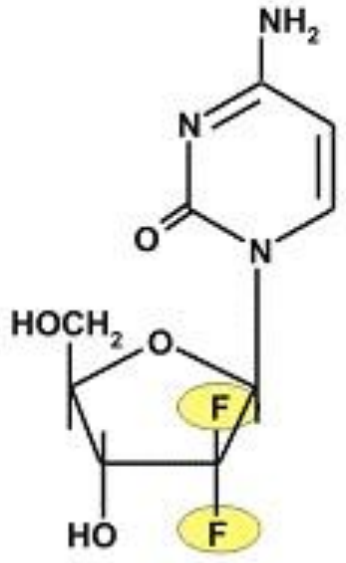

Gemcitabine
SLNs offer additional advantages as drug carrier for cancer targeting due to their nanoscopic size range and high drug loading propensity. High performance liquid chromatography (HPLC) is the most commonly used method for determining the $\mathrm{dFdC}$ concentration in plasma and tissues. $^{10-17}$

\section{MATERIAL AND METHODS}

\subsection{Chemical and reagents}

$(\mathrm{dFdCH})$ was obtained as gift sample from Sun Pharma Laboratories Limited, Vadodara, India, HPLC grade acetonitrile and methanol (Sigma Aldrich, Mumbai, India) were used. Analytical reagent grade (AR) potassium dihydrogen orthophosphate and disodium phosphate (SD Fine Chemicals, Mumbai, India) $(99.5 \%$ purity) were used. Water was purified by Millipore Synergy (Millipore France). The SLNs were synthesized by using specifically the solvent injection method. Mannose anchoring in SLNs was done by ring opening reactions followed by reaction of aldehyde groups of mannose in $0.1 \mathrm{M}$ sodium acetate buffer $(\mathrm{pH} 4.0)$ with the amines groups of SLNs to form M-SLNs ${ }^{18-21}$

\subsection{Instruments}

For chromatography a SIL 10A auto injector HPLC system comprising of SCL 10A system controller, SPD 10A prominence UV/VIS detector, and Shimadzu LC 10 AT pump with LC Solutions software was used (all from Shimadzu Japan). Separation was performed on a Luna Phenomenex ODS C18 HPLC column, $(4.6 \times 250 \mathrm{~mm} ; 5$ $\mu \mathrm{m}$ bead size) maintained at $35^{\circ} \mathrm{C}$. The $\mathrm{pH}$ measurement was carried out by Elico, model LI 120, pH meter equipped with a combined glass-calomel electrode.

\subsection{Chromatographic conditions}

The HPLC analysis was carried out at $35^{\circ} \mathrm{C}$. The compound was chromatographed isocratically with a mobile phase consisting of methanol (HPLC grade): Acetate Buffer $0.1 \mathrm{M}$ (Disodium hydrogen phosphate): $(10: 90 \mathrm{v} / \mathrm{v})$ with the apparent $\mathrm{pH}$ adjusted if required to $5 \pm 0.1$ using Acetic Acid 0.1 M. The mobile phase was filtered by passing through a $0.45 \mu \mathrm{m}$ membrane filter (Millipore, Bedford, MA, USA). The flow rate was 1.5 $\mathrm{mL} / \mathrm{min}$, and the injected volume was $20 \mu \mathrm{L}$. The effluent was monitored spectrophotometrically at wavelength of $269 \mathrm{~nm}^{22}$.

\subsection{Preparation of standard stock and working solutions.}

Heparin rinsed $1 \mathrm{~mL}$ syringe was loaded with $0.1 \mathrm{~mL}$ of heparin solution, and the anaesthetized rats were selected for the standard curve preparation. Organs as liver, spleen, lung and kidney were removed using scissors and forceps, and weighed accurately. Later they were placed in a separate well of a tissue culture plate containing HEPES buffer in freezer for further studies.

Homogenates of various organs were prepared by homogenizing various organs in methanol. To $1 \mathrm{~g}$ tissues of organs the corresponding quantity of stock solution of $\mathrm{dFdCH}$ ranging from $100-5000 \mathrm{ng} / \mathrm{mL}$ was added. The contents were vortexed for $30 \mathrm{sec}$., and kept aside for 30 min. The contents were then treated with $100 \mu$ of acetonitrile to precipitate, again contents were vortexed for $1 \mathrm{~min}$ and $5 \mathrm{~mL}$ methanol was added to it. The mixture was extracted (Cole multipulse vortexer, GlasCol, USA) for $10 \mathrm{~min}$ and centrifuged at $3000 \mathrm{rpm}$ for $10 \mathrm{~min}$. The supernatant was decanted into another vial and evaporated to dryness at $60 \pm 2{ }^{\circ} \mathrm{C}$. The dried residue was reconstituted with $1 \mathrm{~mL}$ methanol and centrifuged at $15000 \mathrm{rpm}$ for $10 \mathrm{~min}$. Clear supernatant was collected in vials and loaded onto the HPLC system (Figure.1).

The standard curve data was obtained in the range of $100 \mathrm{ng} / \mathrm{mL}$ to $5000 \mathrm{ng} / \mathrm{mL}$ (Table.1) The HPLC column $\left(\mathrm{C}_{18}\right.$, Shimadzu, Japan) was washed thoroughly with methanol and then with mobile phase (Methanol/Ammonium acetate buffer; 10:90 v/v; pH 5). The samples starting from blank to increasing concentration were injected and run through the column. 

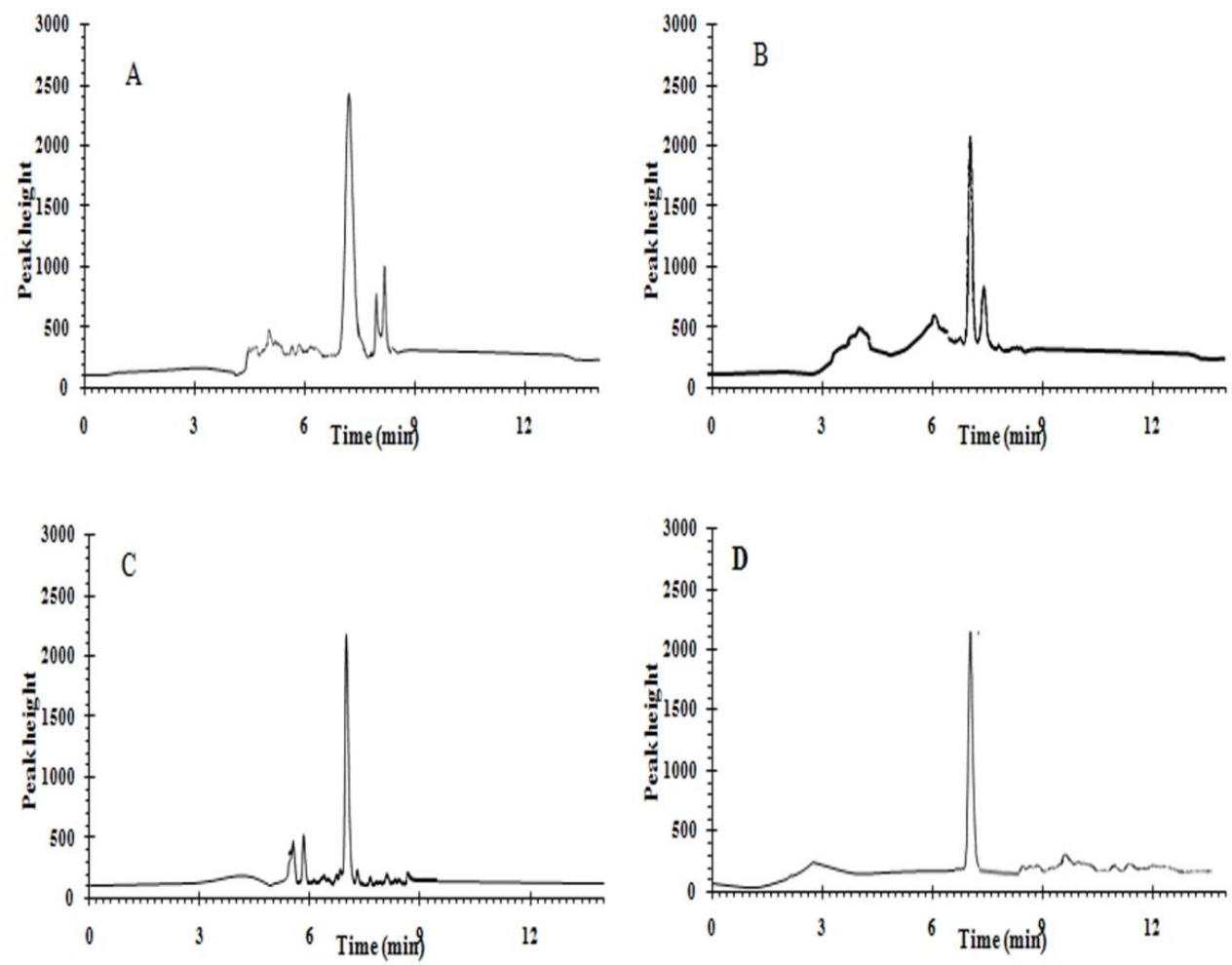

Figure 1: The HPLC chromatograms of dFdCH in (A) kidney, (B) liver, (C), lungs, (D), spleen, in the tissue extracts of Albino rats, $40 \mathrm{~min}$ after infusion of $1000 \mathrm{ng} / \mathrm{mL}$ of $\mathrm{dFdCH}$

Table 1: HPLC standard curve data of $\mathrm{dFdCH}$ in different organs

\begin{tabular}{|c|c|c|c|c|c|}
\hline S.N & Organ & Conc. (ng/mL) & Peak area $\left(\mathrm{mm}^{2}\right)$ & Regressed values & Retention Time \\
\hline 1 & \multirow[t]{7}{*}{ In liver } & 100 & 5979 & 75056 & 7 min \\
\hline 2 & & 500 & 10987 & 24372 & \\
\hline 3 & & 1000 & 61941 & 54846 & \\
\hline 4 & & 2000 & 113882 & 115795 & \\
\hline 5 & & 3000 & 180238 & 176744 & \\
\hline 6 & & 4000 & 239461 & 23694 & \\
\hline 7 & & 5000 & 297014 & 298643 & \\
\hline 1 & \multirow[t]{7}{*}{ In spleen } & 100 & 4987 & 1721 & $7 \mathrm{~min}$ \\
\hline 2 & & 500 & 11998 & 24466 & \\
\hline 3 & & 1000 & 67898 & 57201 & \\
\hline 4 & & 2000 & 126793 & 122671 & \\
\hline 5 & & 3000 & 193496 & 188141 & \\
\hline 6 & & 4000 & 259592 & 252611 & \\
\hline 7 & & 5000 & 309490 & 319081 & \\
\hline 1 & \multirow[t]{7}{*}{ In Lungs } & 100 & 5578 & 7852 & $7 \mathrm{~min}$ \\
\hline 2 & & 500 & 11567 & 26198 & \\
\hline 3 & & 1000 & 65687 & 59928 & \\
\hline 4 & & 2000 & 131074 & 127387 & \\
\hline 5 & & 3000 & 195061 & 194847 & \\
\hline 6 & & 4000 & 262448 & 262306 & \\
\hline 7 & & 5000 & 328235 & 329746 & \\
\hline 1 & \multirow[t]{6}{*}{ In Kidney } & 100 & 5765 & 4169 & $7 \mathrm{~min}$ \\
\hline 2 & & 500 & 18907 & 31897 & \\
\hline 3 & & 1000 & 70946 & 66558 & \\
\hline 4 & & 2000 & 141995 & 135878 & \\
\hline 5 & & 3000 & 209938 & 205199 & \\
\hline 6 & & 4000 & 279784 & 274520 & \\
\hline 7 & & 5000 & 335769 & 331785 & \\
\hline
\end{tabular}




\subsection{Biodistribution studies ${ }^{23}$, (Figure. 2 a \&b)}

For biodistribution studies Albino rats were divided into four groups with three rats in each group. Each group was administered with same intravenous dose of the formulation through tail vein $(10 \mathrm{mg} / \mathrm{g}$ body weight). All rats from each group were sacrificed at 2, 8 and $24 \mathrm{hr}$. The mice organs viz. spleen, kidney, liver and lungs were carefully removed and weighed. Each of these specimens was stored under freeze condition. Weighed tissue samples were immediately homogenized to

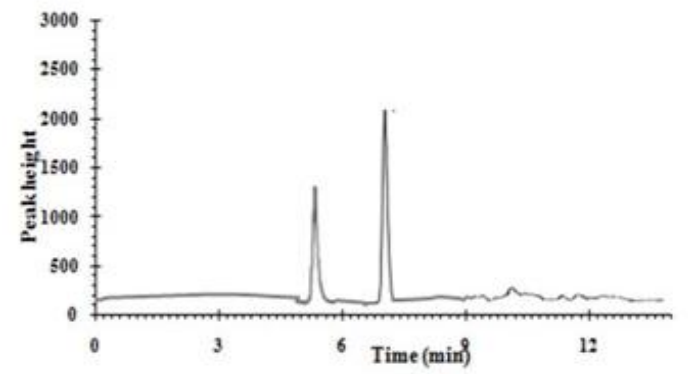

separate the tissues, vortexed for $30 \mathrm{sec}$., and kept aside for $30 \mathrm{~min}$. The contents were then treated with $100 \mu \mathrm{L}$ of acetonitrile, vortexed for $1 \mathrm{~min}$ and then added with 5 $\mathrm{mL}$ methanol. The mixture was extracted (Superfit vortexer, India) and centrifuged at $3000 \mathrm{rpm}$ for $10 \mathrm{~min}$. The supernatant was decanted into another vial and evaporated to dryness at $60^{\circ} \mathrm{C}$. The dried residue was reconstituted with $1 \mathrm{~mL}$ methanol then centrifuged at $15000 \mathrm{rpm}$ for $10 \mathrm{~min}$. clear supernatant was collected in vials and analyzed for $\mathrm{dFdCH}$. (Table. 2)

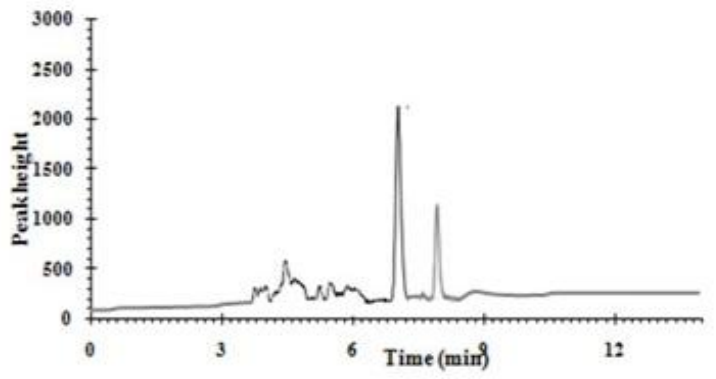

Figure 2a \& 2b: Chromatogram of dFdC-M-SLNs and dFdC-SLNs at10 $\mathrm{mg} / \mathrm{g}$ body weight of rats at $269 \mathrm{~nm}$ in lungs.

Table 2: Comparision of Calibration Standards of (free Gemcitabine) dFdCH, dFdC-PPI and dFdC -M-PPID using HPLC at $\lambda_{\max } 269 \mathrm{~nm}$. in kidney, lungs; Spleen; Liver. At $10 \mathrm{mg} / \mathrm{kg}$ body weight of albino rat

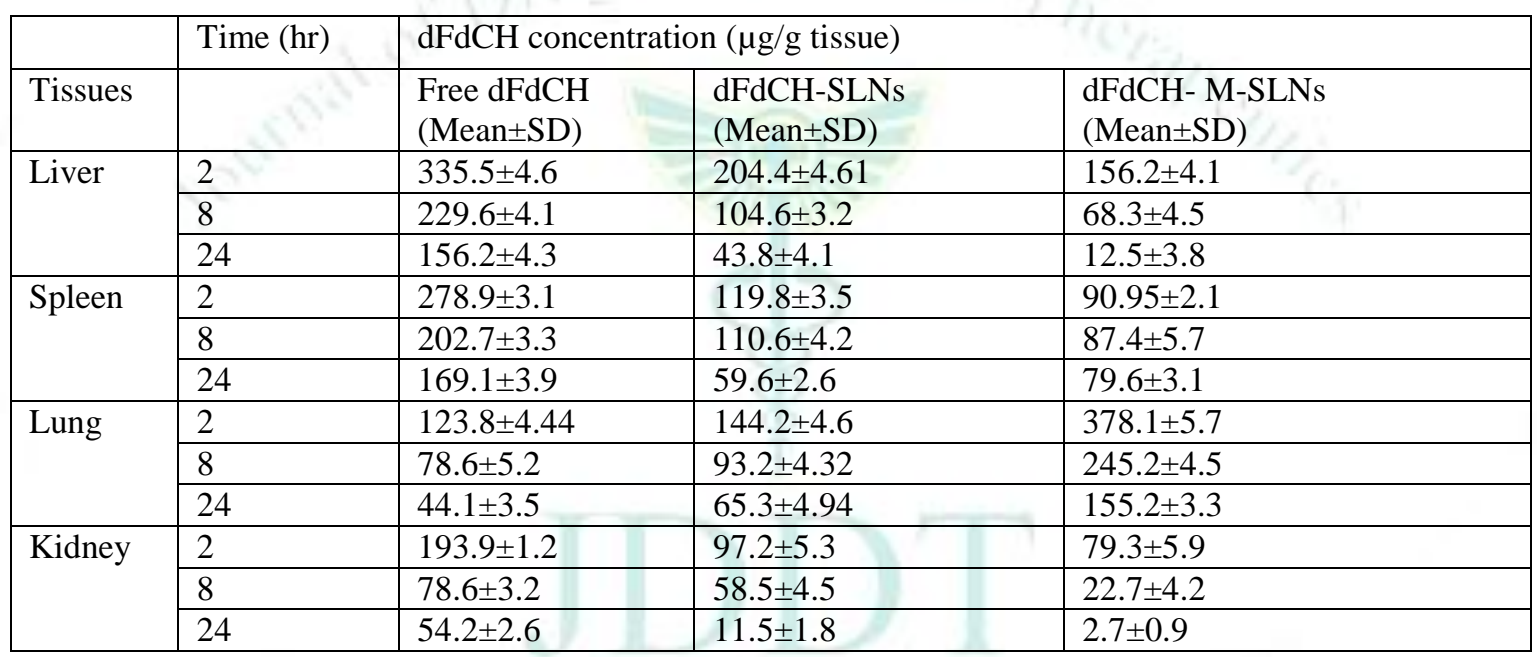

\subsection{Method validation ${ }^{24}$}

The method validation was performed in following ICH guideline according to which the assay validation was performed via various procedures including specificity, linearity, range, accuracy, intra-day and inter-day precision etc. Concentrations of $\mathrm{dFdCH}$ entrapped into SLNs and M-SLNs were determined by three calibration curves run over a three week of period to compare the retention of drug. To determine within -run variation, triplicate samples at seven different concentrations of $\mathrm{dFdCH}$ were prepared in different tissue extracts and injected on the same day. Between run variation was determined by injecting triplicate sample prepared at three different concentrations on three separate occasions.

\section{RESULT AND DISCUSSION}

\subsection{High performance Liquid Chromatography}

$\mathrm{dFdCH}$, monitored at their optimal UV wavelength at $269 \mathrm{~nm}$ based on the UV absorption spectra .To obtain the best chromatographic conditions ,different column, mobile phase with different $\mathrm{pH}$ values were tested to provide sufficient selectivity and sensitivity. Chromatographic separation was performed on a C18 reversed phase column with a mobile phase consisting methanol and ammonium acetate buffer $(10: 90 \mathrm{v} / \mathrm{v})$. The homogenized samples of various tissues were deproteinized with acetonitrile. The results were reproducible and the chromatogram showed a good resolution.

\subsection{Linearity, selectivity and sensitivity}

Calibration curves were plotted between peak area ratios and concentrations of $\mathrm{dFdC}$ in tissues extracts of liver, spleen, lung and kidney respectively, the calibration curves were found to be linear over the concentration range of $100-5000 \mathrm{ng} / \mathrm{mL}\left(\mathrm{r}^{2}=0.9980, \quad \mathrm{r}^{2}=0.9980\right.$, $r^{2}=0.9990, r^{2}=1$ respectively). The calibration curves were obtained by weighed linear regression (weighing factor $1 / \mathrm{x}^{2}$ ) using the Microsoft Excel 2008 software. The limit of quantification (LOQ), the lowest 
concentration of the standard curve can be measured with acceptable accuracy and precision for the analyte was $200 \mathrm{ng} / \mathrm{mL}$. Limit of quantification (LOD), three times of the value of background noice signals was 60 ng/ml (Figure. 3).
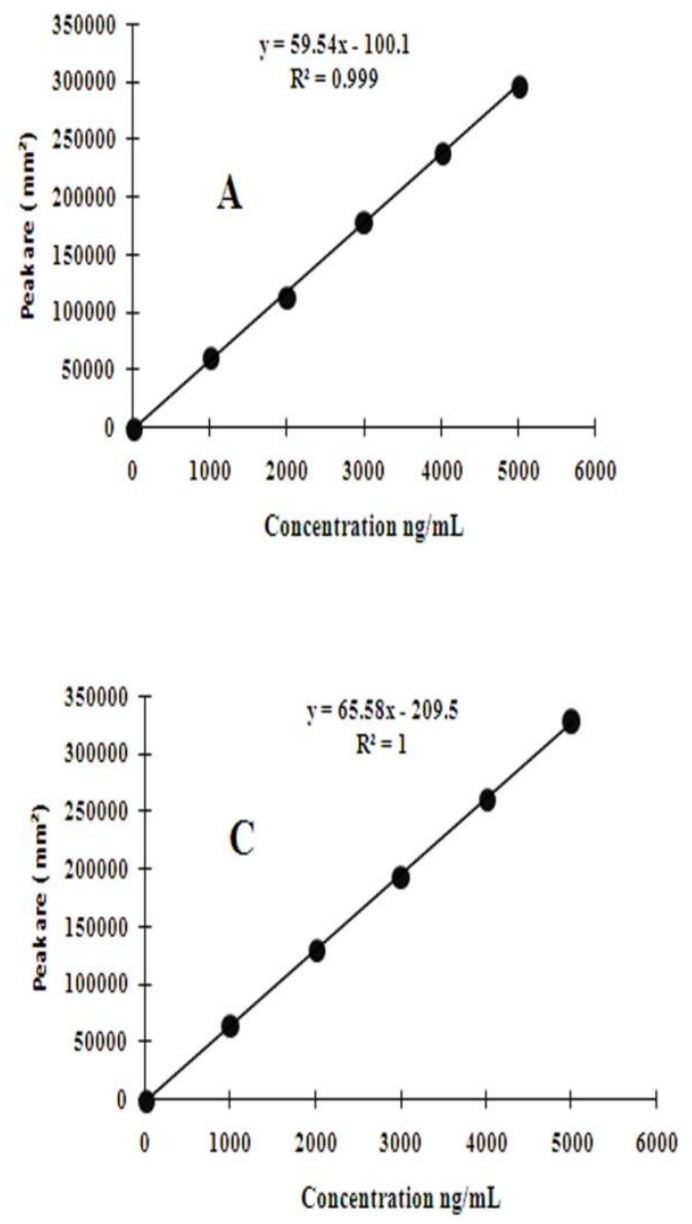

Selectivity of the method was established by blank tissues extract spiked at 1:1 of $\mathrm{dFdC}$. No significant interference observed at the retention time in spiked and blank tissue extracts.
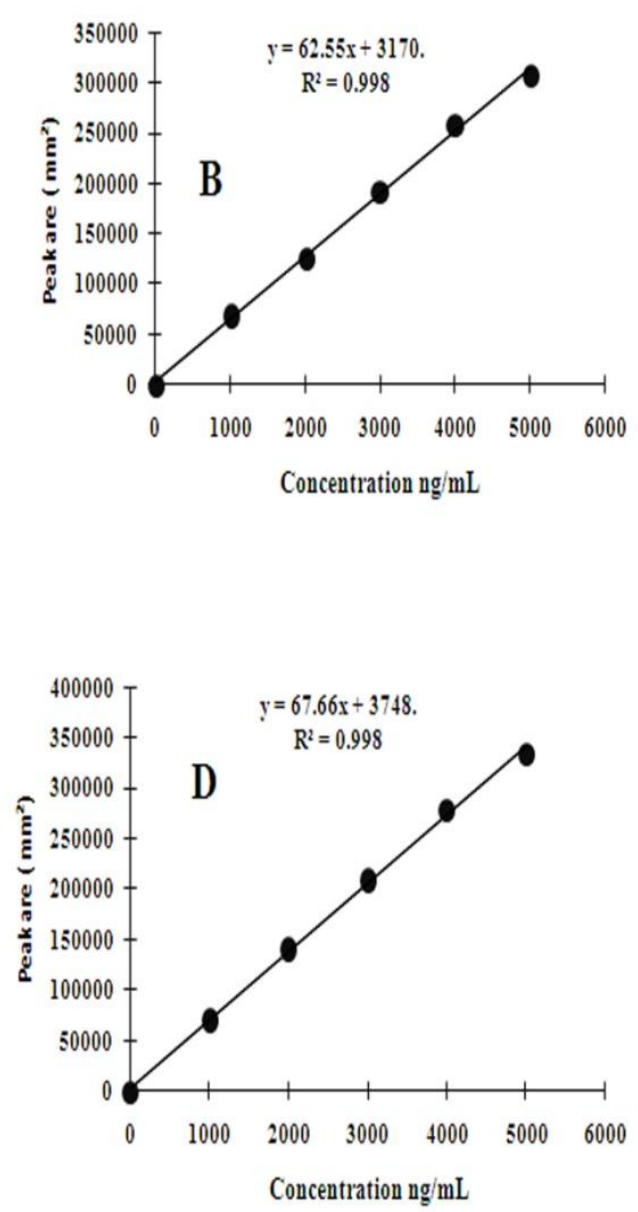

Figure 3: Calibration curves of dFdCH using HPLC at $\lambda_{\text {max }} 269$ nm. A-lungs; B-Spleen; C-Kidney; D-Liver

\subsection{Recovery:}

The recovery of $\mathrm{dFdCH}$ (pure drug) and $\mathrm{dFdCH}$ entrapped SLNs ( $\mathrm{dFdCH}-\mathrm{SLNs}$, dFdCH -M-SLNs) in various tissue extracts (liver, spleen, lung and kidney respectively) at different concentrations was compared to the same concentration in methanol and ammonium acetate buffer $(90: 10 \mathrm{v} / \mathrm{v})$. The recoveries of $\mathrm{dFdCH}$, $\mathrm{dFdCH}-\mathrm{SLNs}$ and dFdCH-M- SLNs were consistent. The overall recovery of all twelve extracts was $76.3 \%$, $78.2 \%, 76.3 \%$. $78.9 \%$ for $\mathrm{dFdC}, 68.2 \%, 70.1 \%, 66.4 \%$, $69 \%$, for dFdC-SLNs, $82.4 \%, 86.4 \%, 85 \%, 83.1 \%$, for dFdCH-M-SLNs.

\subsection{Stability:}

Stock solutions of $100-5000 \mathrm{ng} / \mathrm{ml} \mathrm{dFdC} \mathrm{is} \mathrm{stable} \mathrm{at} \mathrm{-}$ $30^{\circ} \mathrm{C}$ for one month in tissue extracts but stock solutions of formulations at same concentrations in same medium is less stable. They are stable for two weeks at $-40^{\circ} \mathrm{C}$.

\subsection{Accuracy and Precision}

Intra - day and inter - day precision and accuracy were determined at seven concentrations for pure drug and formulations. Intra -day precision was determined by comparing peak heights of each sample on same day $(n=3)$. Inter -day precision was determined over a 3week period.

\section{CONCLUSION}

In this study a simple and rapid bioanalytical assay method has been developed and validated in various tissue extracts. The validated method was demonstrated to be accurate, precise, selective and sensitive. The method was found to be linear $\left(r^{2}=0.9980, r^{2}=0.9980\right.$, $r^{2}=0.9990, r^{2}=1$ respectively) within the analytical range of $100-5000 \mathrm{ng} / \mathrm{mL}$. A maximum recovery of the drug from the tissue extracts resulted. The present assay method was carried out with extensive validation parameters as per ICH guidelines. The drug was stable in extracts and developed method was used in biodistribution studies. The present work establishes suitability of mannosylated SLNs to target $\mathrm{dFdcH}$ in lungs. Encapsulation of $\mathrm{dFdCH}$ in mannosylated SLNs enhances the residence time as well as concentration of drug in lung which could be useful in reducing the dosing frequency as well as dose. This could help in reduction of toxicity associated with this anticancer bioactive. 


\section{REFERENCES}

1. Block JH, Beale JM, Wilson Jr, Giswold's Organic Medicinal and Pharmaceutical Chemistry, eleventh ed., Lippincott Williams \& Wilkins, 2004, 407.

2. Williams DA, Lemke TL, Foye's Principle of Medicinal Chemistry, fifth ed., 2002, 936.

3. Kleespies A, Jauch KW, Bruns CJ, Drug Resistance Updates 2006; 9:1-18.

4. Xu J, Zhou Y, Zhang J, Chen Y, Zhuang R, Liu T, Cai W, Clinica Chimica Acta 2012; 413:1284-1287.

5. Adachi S, Yasuda I, Kawaguchi J, Yamauchi Nakashima TM, Itani M, et al, Biochemical and Biophysical Research Communications 2011; 414:53-59.

6. Imen A, Amal K, Ines Z, Sameh EF, Fethi EM, Habib G, Respiratory Medicine, 2006; 100:14631465.

7. Pauwels B, Korst AEC, de Pooter CMJ, Lambrechts H.A.J., Pattyn G.G.O., Lardon F, Vermorken J.B., European Journal of Cancer 2003; 39:838-846

8. Medina SH, Md. E. H. El-Sayed Chem. Rev. 2009; 109:3141-3157.

9. Peterson J, Ebber A, Allikmaa V, Lopp M, Proc. Estonian Acad. Sci. Chem., 2001; 50(3):156-166.

10. Keith B., Y. Xu, J. L., J. Chromatography B, 2003; 785:65-72.

11. Hasan N, Chaiharn M, Khalid H, Jabbar A, Pharm Anal Acta 2013; 4(8):1000263.

12. Thippani R, Pothuraju NR, Ramisetti NR, Shaik S, Journal of Pharmaceutical Analysis, article in press.

13. Cheng X, Guo L, Li Z, Li L, Zhou T, Lu W, Journal of Chromatography B, 2013; 915-916:64-70.
14. Lin H, Gounder MK, Kong AT, Dipaola RS, Journal of Pharmaceutical and Biomedical Analysis, 2012; 66:371-375.

15. Ulu ST, Journal of Pharmaceutical and Biomedical Analysis, 43; 2007:1444-1451.

16. Liu M, Wang J, Wu X, Wang E, Baptista D, Journal of Pharmaceutical and Biomedical Analysis, 2014; 89: 34-41.

17. Cattel L, Airoldi M, Delprino L, Passera R, Milla P, Pedani F, Annals of Oncology 2006; 17 (5):142147.

18. De Brabander-van Den Berg E M M, Meijer E W. Poly(propylene imine) SLNs: Large-Scale Synthesis by Hetereogeneously Catalyzed Hydrogenations. Angew. Chem. Int. Ed. Engl., 1993; 32:1308-1311.

19. Kumar P.V., Agashe H., Dutta T. Jain NK, Curr. Drug Deliv., 2007; 3:000-000

20. Kumar P.V., Agashe H., Dutta T. Jain NK, J. Drug Targeting, 2006; 14:546-556.

21. Caminade AM. Laurent R, Majoral JP,. Adv. Drug. Del. Rev., 2005; 57:2130-2146.

22. Indian Pharmacopoeia, Govt. of India, Ministry of Health and Family Welfare, New Delhi. 2007, I: 323.

23. Pasut G, Canal F, Via DL, Arpicco S, Veronese FM, Schiavon O, Journal of Controlled Release 2008; 127:239-248.

24. ICH-Q2B (2005) Guideline for Industry, Q2B Validation of Analytical Procedure: Methodology. International Conference on Harmonisation, Food and Drug Administration, U.S. Department of Health and Human Services. 